\title{
Roflumilast in COPD: a Brazilian perspective
}

\section{Roberto Stirbulov' José R Jardim²}

'Department of Respiratory Diseases, Santa Casa School of Medical Sciences in São Paulo, ${ }^{2}$ Department of Respiratory Diseases, Escola Paulista de Medicina, Federal University of São Paulo, Hospital São Paulo, São Paulo, Brazil
Correspondence: Roberto Stirbulov Department of Respiratory Diseases, Santa Casa School of Medical Sciences in São Paulo, Rua Dr José Ferraz de Oliveira 100, São Paulo 04645-010, Brazil

Email stirbulov@uol.com.br
This article was published in the following Dove Press journal:

International Journal of COPD

8 September 2015

Number of times this article has been viewed

\section{Dear editor}

We would like to discuss the use of roflumilast in Brazil and its perspectives, based on the data currently available. This medication is underused in Brazil, probably due to its high cost in the public health care system. Of the approximately 21,000 patients who have a condition which could be treated with roflumilast (personal communication, Takeda Pharmaceutical Company, 2014), only 14\% are currently using it.

Chronic obstructive pulmonary disease (COPD) is a progressive inflammatory condition that currently affects between 3 and 7 million Brazilian citizens. As per DATA-SUS (Department of Data Analysis of the Brazilian Public Health System), COPD in 2010 led to 141,994 hospitalizations, 778,428 hospitalization days, a total cost of US\$30.4 million, and led to 7,937 deaths directly related to COPD, which ranks 5th as cause of death in Brazil. ${ }^{1}$ According to the PLATINO study, the prevalence of COPD in Brazil is $15.8 \%$ in adults over the age of 40 years. ${ }^{2}$

Patients with severe and very severe COPD usually suffer at least one exacerbation per year. COPD patients with chronic bronchitis for example, have twice as many exacerbations per year as patients without chronic bronchitis, and these patients are at an increased risk of hospitalization and death. Each exacerbation can last from a few days to several weeks, longer including the recovery period. ${ }^{3}$

COPD exacerbation enhances the systemic effects of inflammation, which increases the risk of cardiovascular and cerebrovascular events by up to 2.27 times during the first 5 days after an exacerbation. Thus, a reduction in the frequency of exacerbations brings an additional positive effect on reducing cardiovascular risk. ${ }^{4,5}$ Data from recent studies have clearly demonstrated the life-threatening potential of this condition. ${ }^{3}$ Suissa et al showed using a large retrospective cohort of COPD patients, that the median time between consecutive severe exacerbations declined with every new episode, and that a $50 \%$ mortality rate following the first hospitalization for severe exacerbation was 3.6 years. ${ }^{3}$ Despite the high mortality observed after an COPD exacerbation episode (23\%), exacerbations do not raise the same concerns as myocardial infarction which presents a mortality rate of $9.6 \%$ after 1 year. ${ }^{6}$

Persistent systemic inflammation has been recognized in patients with stable COPD, as well as its relationship in the risk of exacerbations, which in turn further aggravate systemic inflammation, possibly contributing to the increased risk of myocardial infarction and stroke. This data suggests that preventing exacerbations with strategies directly targeting inflammation may have the potential to impact morbidity in patients with COPD. ${ }^{7}$

Roflumilast is an innovative oral anti-inflammatory drug with a unique mechanism to treat severe, and very severe COPD associated with chronic bronchitis in adult patients with recurrent episodes of exacerbations. This may contribute to a decrease 
in the consumption of various health resources, such as hospital admissions, examinations, and additional medication. Roflumilast is used as an add-on drug with a bronchodilator, having an adjuvant effect in this group of patients.

The intended effect of roflumilast to-date is to reduce the risk of exacerbation in COPD patients. Based on its antiinflammatory effects, the drug has a mild indirect effect on improving lung function. Due to its oral use, roflumilast is distributed to the lungs via systemic circulation and therefore may be able to reach lower airway inflammation, which can be out of range from inhaled medications, particularly in patients with a high degree of obstruction and mucus production. Roflumilast, due to being an oral treatment taken on a daily basis, may have an added favorable impact on the overall adherence to therapy of COPD. ${ }^{8}$

A meta-analysis of eleven clinical trials $(\mathrm{N}=9,675 \mathrm{COPD}$ patients) in which roflumilast was compared to a placebo (with or without other pharmacological therapies), and whose primary endpoint also included exacerbation rates, found that roflumilast significantly decreased the mean exacerbation rate by $23 \% .^{9}$ Phase II (AURA) and Phase III (HERMES) clinical trials reported that treatment with roflumilast in order to prevent one moderate or severe exacerbation per year was 5.29 and 3.64, respectively (NNT, number of patients needed to treat to prevent one exacerbation), ${ }^{10}$ a lower value than the NNT for statins in the secondary prevention setting, which ranges from 8 to 28 in a timeframe of 5 years. ${ }^{11}$ However, further studies are necessary to increase the robustness of these observed findings.

The React study showed that roflumilast reduced exacerbations and hospital admissions in patients with severe COPD and chronic bronchitis, who were at risk for frequent and severe exacerbations, despite undergoing inhaled corticosteroid and long-acting $\beta 2$-agonist therapy, even in combination with tiotropium. ${ }^{12}$

That approximately 5 million Brazilians over a 40 year period have COPD, and that the public health system only provides treatment for 319,166 patients, ${ }^{2}$ emphasizes the under treatment of COPD in Brazil. According to this estimate, the number of severe to very severe patients eligible for roflumilast in Brazil would be approximately 21,449 patients. $^{13}$

Sales data obtained indicate that 106,462 units of roflumilast were sold from June 2011 (launching) to November 2014 (personal communication, Takeda Pharmaceutical Company, 2014), to the approximately 3,000 patients treated during this period. Considering that the roflumilast target in Brazil is 21,449 patients, approximately $14 \%$ of the targeted population are being treated so far.
Other drugs available for the treatment of stable COPD, which are provided free of charge through the Brazilian public health system so long as a patient meets the clinical protocol are: ipratropium bromide, salmeterol, formoterol, budesonide, and fluticasone. Roflumilast and long-acting anti-muscarinic drugs are not on the list of medicines provided free through the public health system. Patients with the exacerbator phenotype are treated with the combination of inhaled corticosteroids and long-acting $\beta 2$-agonists. This explains why only $14 \%$ of patients who would benefit from taking roflumilast in Brazil are utilizing this drug. In addition, the relatively high price (US\$35.00; $8 \%$ of minimum monthly wage), which is expensive for the average Brazilian population, and the gastrointestinal side effects that some patients have, ${ }^{9}$ collaborate to its underutilization.

We may conclude that one of the reasons for the low rate of roflumilast use in Brazil may be that it has not yet been included on the formal public health system list for free drug distribution. ${ }^{14}$ In addition, the relatively high cost of the drug in regards to the average Brazilian's income may also be another reason. However, there is high potential for its use, in light of the significant percentage of the exacerbator phenotype among the severe and very severe COPD patients in the Brazilian population.

\section{Disclosure}

The authors report no conflicts of interest in this communication.

\section{References}

1. DATASUS [webpage on the Internet]. Ministry of Saúde, Brazil. Availaible from: http://www2.datasus.gov.br/DATASUS/index.php. Accessed December 15, 2014.

2. Menezes AM, Perez-Padilla R, Jardim JR, et al. Chronic obstructive pulmonary disease in five Latin American cities (the PLATINO study): a prevalence study. Lancet. 2005;366(9500):1875-1881.

3. Suissa S, Dell'Aniello S, Ernst P. Long-term natural history of chronic obstructive pulmonary disease: severe exacerbations and mortality. Thorax. 2012;67(11):957-963.

4. Armstrong PW, Fu Y, Chang WC, et al. Acute coronary syndromes in the GUSTO-IIb trial: prognostic insights and impact of recurrent ischemia. The GUSTO-IIb investigators. Circulation. 1998;98(18):1860-1868.

5. Feary JR, Rodriques LC, Smith CJ, Hubbard RB, Gibson JE. Prevalence of major comorbidities in subjects with COPD and incidence of myocardial infarction and stroke: a comprehensive analysis using data from primary care. Thorax. 2010;65(11):956-966.

6. Hawkins NM, Huang Z, Pieper KS, et al. Chronic obstructive pulmonary disease is an independent predictor of death but not atherosclerotic events in patients with myocardial infarction: analysis of the Valsartan in Acute Myocardial Infarction Trial (VALIANT). Eur J Heart Fail. 2009;11:292-298.

7. Fabbri LM, Rabe KF. From COPD to chronic systemic inflammatory syndrome? Lancet. 2007;370(9589):797-799.

8. Price D, Chisholm A, Ryan D, Crockett A, Jones R. The use of roflumilast in COPD: a primary care perspective. Prim Care Respir J. 2010;19(4): 342-351. 
9. Yan JH, Gu WJ, Pan L. Efficacy and safety of roflumilast in patients with stable chronic obstructive pulmonary disease: a meta-analysis. Pulm Pharmacol Ther. 2014;27(1):83-89.

10. Kim S, Clark S, Camargo CA Jr. Mortality after an emergency department visit for exacerbation of chronic obstructive pulmonary disease. COPD. 2006;3:75-81.

11. Ebrahim S, Smith GD. Statins and risk of coronary heart disease. JAMA. 2000;283(22):2935-2936

12. Martinez FJ, Calverley P, Goehring LM, Brose M, Fabbri LM, Rabe KF. Effect of roflumilast on excacerbations in patients with severe chronic obstructive pulmonary disease uncontrolled by combination therapy (REACT): a multicentric randomized controlled trial. Lancet. 2015;385(9971):857-866.
13. Ministério da Saúde-Secretaria de Atenção à Saúde-portaria n ${ }^{\circ} 609$, de 6 de junho de 2013. Protocolo Clínico e Diretrizes Terapêuticas Doença Pulmonar Obstrutiva Crônica. 2013;108(1):36.

14. Nascimento OA, Camelier A, Rosa FW, et al. Chronic obstructive pulmonary disease is underdiagnosed and undertreated in São Paulo (Brazil): results of the PLATINO study. Braz J Med Biol Res. 2007; 40(7):887-895.

Dove Medical Press encourages responsible, free and frank academic debate. The content of the International Journal of Chronic Obstructive Pulmonary Disease 'letters to the editor' section does not necessarily represent the views of Dove Medical Press, its officers, agents, employees, related entities or the International Journal of Chronic Obstructive Pulmonary Disease editors. While all reasonable steps have been taken to confirm the content of each letter, Dove Medical Press accepts no liability in respect of the content of any letter, nor is it responsible for the content and accuracy of any letter to the editor.

International Journal of COPD

\section{Publish your work in this journal}

The International Journal of COPD is an international, peer-reviewed journal of therapeutics and pharmacology focusing on concise rapid reporting of clinical studies and reviews in COPD. Special focus is given to the pathophysiological processes underlying the disease, intervention programs, patient focused education, and self management protocols.

\section{Dovepress}

This journal is indexed on PubMed Central, MedLine and CAS. The manuscript management system is completely online and includes a very quick and fair peer-review system, which is all easy to use. Visit http://www.dovepress.com/testimonials.php to read real quotes from published authors.

Submit your manuscript here: http://www.dovepress.com/international-journal-of-chronic-obstructive-pulmonary-disease-journal 